Article

\title{
A Hybrid RES Distributed Generation System for Autonomous Islands: A DER-CAM and Storage-Based Economic and Optimal Dispatch Analysis
}

\author{
Panagiotis Michalitsakos $^{1}$ (D), Lucian Mihet-Popa ${ }^{2, *}$ (i) and George Xydis ${ }^{3}$ \\ 1 Heriot-Watt University, School of Engineering and Physical Sciences, Edinburgh Campus, \\ Edinburgh EH14 4AS, UK; michalitsakos.pan@gmail.com \\ 2 Faculty of Engineering, Østfold University College, Kobberslagerstredet 5, 1671 Kråkeroy, Norway \\ 3 Department of Business Development and Technology, Aarhus University, Birk Centerpark 15, \\ 7400 Herning, Denmark; gxydis@btech.au.dk \\ * Correspondence: lucian.mihet@hiof.no; Tel.: +47-6960-8756
}

Received: 5 September 2017; Accepted: 30 September 2017; Published: 2 November 2017

\begin{abstract}
The possibility of replacing the existing autonomous thermal power plants by Distributed Energy Resources (DER) based on renewable energy sources (RES), along with the appropriate energy storage technologies in order to deal with the major problems that autonomous islands usually face was investigated. A case study of a small Greek island, which is confronted by various energy and water shortages, was studied for assessing the feasibility of DER deployment. The main objectives investigated were cost minimization, $\mathrm{CO}_{2}$ emissions minimization and DER reliability maximization. The DER-CAM (Distributed Energy Resources Customer Adoption Model) decision support tool was used for the multi-objective analysis conducted, which proposes a set of optimal solutions defining the appropriate Distributed Generation (DG) technologies, the capacities of storage and other technologies and the optimal dispatch of the DG system. A mutual beneficial solution, for all stakeholders, was proposed indicating the scope for developing such systems for all islands facing the same problems.
\end{abstract}

Keywords: distributed generation; DER-CAM; distributed energy resources

\section{Introduction}

The aim of this study was to deal with the major problems that autonomous islands face (specifically, non-interconnected Greek islands). The possibility of replacing the existing autonomous power plants with RES-based local units along with the appropriate energy storage technologies was investigated. The exploitation of the abundant renewable energy resources of the Aegean Archipelagos area is expected to lead to a cleaner and less expensive alternative to the existing oil-dependent electricity generators.

The DER-CAM (Distributed Energy Resources Customer Adoption Model) decision support tool is used for multi-objective planning optimization of RES-based Distributed Energy Resources (DER) [1]. In order to find optimal DER investments, three main scenarios are considered:

- Economical optimization, so as to minimize the cost of operation and on-site generation

- Environmental optimization, so as to minimize $\mathrm{CO}_{2}$ emissions ( $100 \%$ autonomous operation)

- A weighted objective that simultaneously considers the above criteria

The above scenarios are evolved under various perspectives of the stakeholders. By running the DER-CAM optimization model, the following aspects are addressed: 
- Cost-optimal configuration of Renewable Energy Technologies (RETs)

- Appropriate level of installed capacity

- How installed capacity can be operated.

Tilos Island belongs to the island complex of Dodecanese, on the southeastern part of the Aegean Sea, and is interconnected with the grid of Kos and Kalymnos Islands via an underwater sea-cable. Kos and Kalymnos are non-interconnected with the mainland grid and have installed a thermal plant of 120.05 MW capacity, which covers their demand and feeds a small cluster of nine islands.

The project's main goal is to demonstrate the potential of local/small-scale battery storage to serve a multi-purpose role within an island micro-grid that also interacts with a main electricity network. Among others, the project aims to achieve large-scale RES penetration and asset value maximization through the optimum integration of a hybrid RES (wind and PV) power station together with advanced battery storage, distributed, domestic heat storage, smart metering and DSM.

The data that were used in the study are based on either estimations or measurements that have been conducted for the project needs. Data on load demand and power outages for Tilos Island were provided to the first author of the paper under the frames of the Heriot Watt MSc in Energy program in order to conduct his MSc thesis [2]. Supplementary data such as ambient temperature or other missing data were assumed. Since data for 2013 regarding load demand were obtained, it was assumed that practically for such a small island, no significant changes are expected.

\section{Literature Review}

Much work has been done in the field, especially by using DER-CAM as an optimization microgrid tool. A number of hybrid RES-based DG systems are studied including storage facilities being interconnected with the local grid or not. Momber et al. [3] used the tool to examine the viability of a system composed of an Electric Vehicle (EV) and a building's energy management system. The study showed that the implementation of such a concept could be beneficial for both the end-user and the grid. Another study following after this one, focused on EVs and the buildings' demand working on decision support and scheduling problems [4]. Mendes et al. pointed out that DER-CAM is the appropriate tool to be used when it comes to microgrid simulations in comparison to other available tools, due to the robust and flexible three-level optimization algorithm the tool uses [5]. A detailed storage and economic analysis exploiting the natural synergy with the buildings' demand was implemented by Beer et al. [6]. The researchers concluded that the battery usage shall be optimized by installing battery packs in the buildings' microgrids. Optimization of thermal storage systems via the use of DER-CAM under various economic and climate conditions was also studied by DeForest et al. [7], while CHP systems [8] and reduced greenhouse emissions in shopping centers [9] were also approached by the utilization of the tool.

However, significant work has been published on the design and operation optimization of DER through the multi-objective approach, without the utilization of the DER-CAM tool. Alarcon-Rodriguez et al. [10] published a detailed state-of-the-art work, presenting novel methods that have been proposed so far, discussing the trends, challenges and all the latest developments in the area. Ren et al. [11] followed the multi-objective approach focusing more on the economic and environmental aspects similar to the case of DER-CAM. DER is linked with smart grids and multi-objective optimization, and significant work has been published to illustrate this [12,13]. Works on measurements and innovative communication systems have also been published in correlation with the multi-objective approach [14-18].

\section{Methodology}

The objective of the model was to minimize the cost of the on-site generation and the Combined Heat and Power (CHP) systems during operation, either for individual customer sites or a microgrid. In other words, the focus of this work was predominantly economic. 
The load profile of Tilos Island was one of the key inputs of the DER-CAM optimization process. DER-CAM considers the load demand as the hourly average value per month, defined over three different day types: week days, weekend days and peak days. Figure 1 shows the load profile of Tilos Island (a), the load profile of the 9-island complex (b), the average annual ambient temperature (c) and the wind speed measurements for Tilos Island (d).

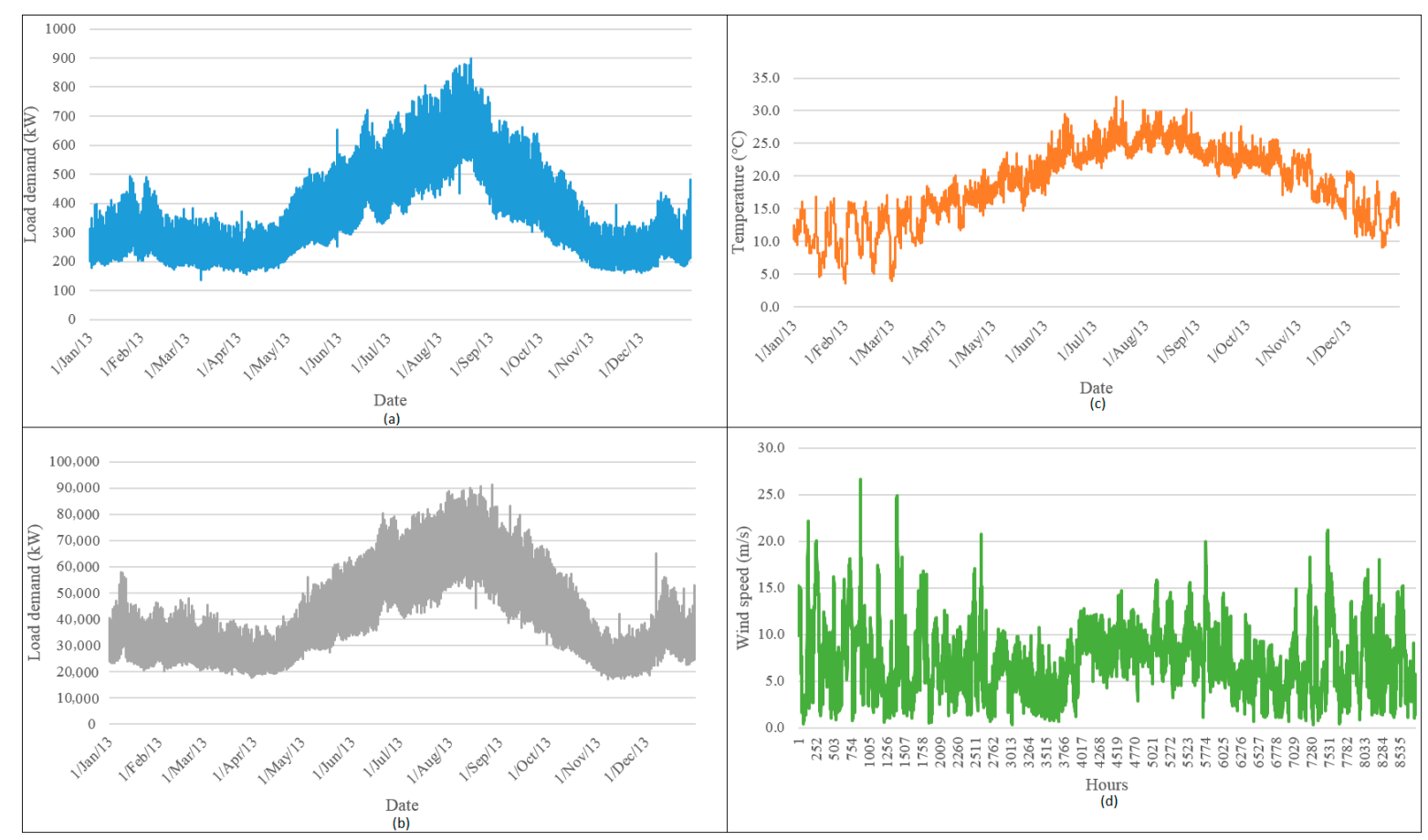

Figure 1. Load profile of Tilos Island (a); the load profile of the 9-island complex (b); the average annual ambient temperature (c); and the wind speed measurements for Tilos Island (d).

The load profile for the entire island complex helps us to acquire a comprehensive overview of the local power grid as a whole. This was used for creating time bands during a day and thus enabling the time of use rates. The time bands are defined by three time categories: peak, mid-peak and off-peak hours. The ambient temperature is correlated with the efficiency of photovoltaic and solar thermal panels and was used as the input to calculate the power generation produced by photovoltaic panels. A wind measurement mast has been installed on Tilos Island, so that the local wind potential can be measured. Although the wind speed values cannot be used directly as input to DER-CAM, they are used for computing the theoretical power output.

One of the most important reasons behind this study was the issues confronted by the islanders in relation to the power cuts and low quality of power offered, which have an immediate impact on the local businesses and daily life. A great number of power interruptions is commonplace for the islanders (Figure 2).

The number and the duration of grid outages can be modelled in DER-CAM using the corresponding number of days (emergency days).

For the multi-objective problem of DG optimization from the DER developer perspective, the main objective is clearly economic, aiming at maximizing the profits. On the one hand, the Distribution System Operator (DSO) is interested in reducing grid losses and postponing investments related to the network's enhancement. On the other hand, local communities are interested in the power quality, as well as the level of autonomy that they can achieve. The final goal of this study was to find the best solution for each stakeholder individually, resulting in a compromise solution, beneficial for all stakeholders (win-win solution). 


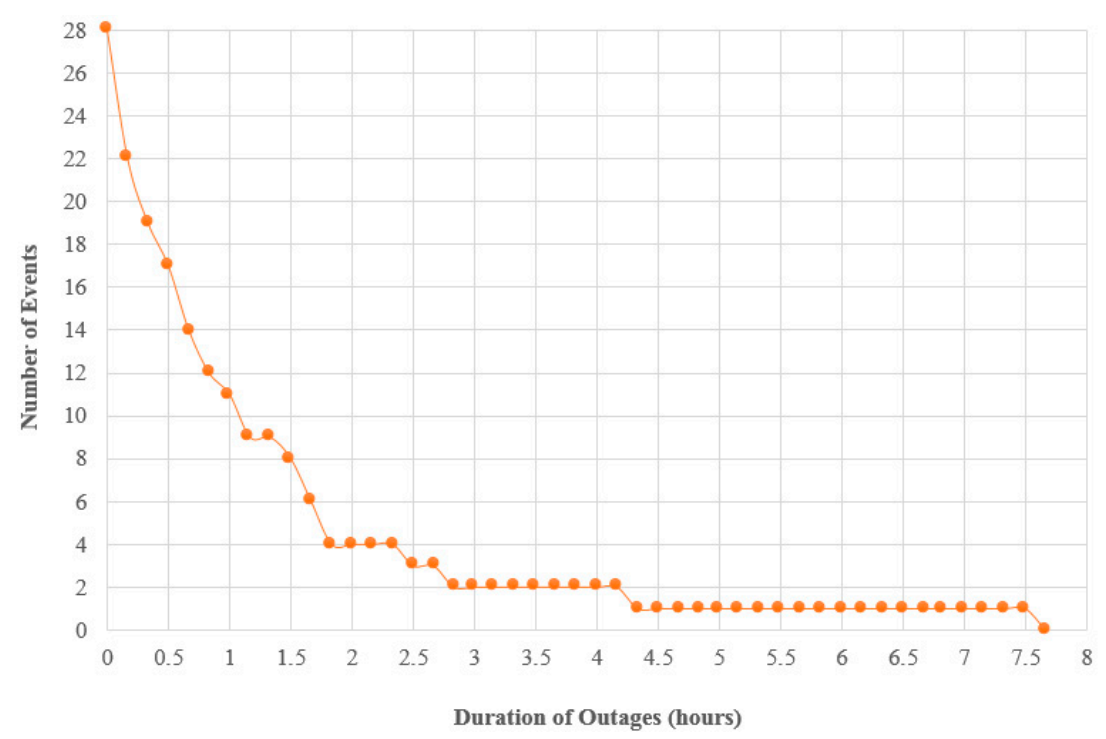

Figure 2. Duration curve of outages in Tilos Island (4 April-17 December 2015).

For the needs of this research, Tilos Island is considered a microgrid as a whole, with active energy management for both DERs and the distribution network available, so as to achieve optimum energy dispatch. The existing situation was defined, and the reference costs and $\mathrm{CO}_{2}$ emissions were taken into account. The load demand in the format of hourly load profiles per month, for three different day-types (week, weekend and peak), was set. The loads were defined as the following types: electricity-only, electric cooling, electric refrigeration, space heating, water heating and natural gas. Electric cooling and electric refrigeration loads were considered as electricity-only loads, since no detailed information was available. Utility electricity tariffs were also defined accordingly in the tool. Therefore, the marginal electricity generation cost of the entire 9-island complex, plus $\mathrm{CO}_{2}$ taxes, is defined as electricity rates and is inserted into the corresponding field.

In order to take advantage of the feature of DER-CAM, regarding the optimal electricity dispatch output and the marginal cost of electricity generation, $\mathrm{CO}_{2}$ taxes included, these have been converted to ToU (time of use) rates. The time categories that have been defined on a seasonal basis are: peak, mid-peak and off-peak hours, using the list of hours table. Power demand charges and utility monthly access fee were not considered. Based on the Energy Package, which aims at reducing the EU's greenhouse gas emissions by $20 \%$ in 2020 (compared to 1990) [10] and the national decisions, the $\mathrm{CO}_{2}$ allowance price was set at $4 € /$ tn $[11,19]$.

The available generation and storage technologies in the tool are divided into two categories: discrete and continuous. The optimal capacity of discrete technologies is determined as a discrete number of units, whereas the capacity of continuous technologies is determined by a continuous variable. The rated wind energy capacity chosen was $50 \mathrm{~kW}$ in order to give flexibility in the design process. The capital cost of a 50-kW wind turbine was set at 65,000 $€$ including installation costs, while the fixed annual maintenance cost per generator was set at $975 €$ and the variable wind generator maintenance cost at $0.0022 €$ per $\mathrm{kWh}$ produced. From the continuous generation technologies, PV seems to be appropriate because of the abundant solar radiation, together with electric storage based on batteries. The variable investment cost for PV technology was set at $1100 € / \mathrm{kW}$ installed, and the fixed operational and maintenance cost was set at $0.92 € / \mathrm{kW}$, while for the batteries, the relative costs were $1000 € / \mathrm{kWh}$ and $0.83 € / \mathrm{kWh}$ respectively [2,20-27].

Furthermore, the maximum charge/discharge rate of the batteries was defined at $33 \%$ and the minimum stage of charge $10 \%$ of the total capacity, with a discrete capacity size of $22.5 \mathrm{kWh} / \mathrm{unit}$.

Furthermore, load curtailment energy management techniques have been considered when the utility is unavailable and the microgrid is in forced islanding mode. If the energy demand is greater 
than the local generation capacity and available storage, a percentage of the load will necessarily be curtailed. This is done with respect to the cost to the microgrid, which is associated with the loss of service. Demand management techniques were not taken into account; planning optimization was not seen from the end-user viewpoint. Although in Greece, the DSO is not bound to any compensation due to energy supply interruptions, in some countries, this is an important matter. In order to estimate this cost, the Interruption Cost Estimate (ICE) Calculator on-line tool (Table 1) was used [12].

Table 1. Input values for Interruption cost Estimate Calculator (ICE). SAIFI, System Average Interruption Frequency Index; SAIDI, System Average Interruption Duration Index; CAIDI, Customer Average Interruption Duration Index.

\begin{tabular}{cccc}
\hline & \multicolumn{3}{c}{ Input Values } \\
\hline SAIFI & 30 & No. of Non-Residential Customers & 50 \\
SAIDI (in hours) & 44.8 & No. of Residential Customers & 200 \\
CAIDI (in hours) & 1.5 & & \\
\hline
\end{tabular}

The System Average Interruption Frequency Index (SAIFI), System Average Interruption Duration Index (SAIDI) and Customer Average Interruption Duration Index (CAIDI) are reliability indicators of the distribution system (Equations (1)-(3)) [13]:

$$
\begin{gathered}
\text { SAIFI } \left.=\frac{\sum_{i} \lambda_{i} N_{i}}{\sum_{i} N_{i}} \text { (times/customer } \times \text { year }\right) \\
\text { SAIDI } \left.=\frac{\sum_{i} U_{i} N_{i}}{\sum_{i} N_{i}} \text { (hours/customer } \times \text { year }\right) \\
\text { CAIDI } \left.=\frac{\sum_{i} U_{i} N_{i}}{\sum_{i} U_{i} N_{i}} \text { (hours/event }\right)
\end{gathered}
$$

where $\lambda_{i}$ is the failure rate of load point $i, N_{i}$ is the quantity of customers and $U_{i}$ is the yearly interruption hours of load point $i$. In this case, $i$ is Tilos Island, $\lambda$ was 30 interruptions, $N$ was 790 inhabitants and $U$ was approximately $45 \mathrm{~h}$ during 2015. According to Eurostat official data [14], the electricity consumption per capita in the residential sector in Greece, in 2013, was 1.6 MWh. Furthermore, according to the last population census conducted in 2011 by the Hellenic Statistical Authority, the population of Tilos Island was 790 residents.

Assuming that each household consists of 4 persons, the residential customers are approximately 200 , and the total residential consumption is about $790 \times 1.6=1264 \mathrm{MWh} /$ year. As the annual energy consumption of Tilos Island was $2936 \mathrm{MWh}$, the rest of the energy demand from small Commercial and Industrial (C\&I) customers was: $3209-1264=1945 \mathrm{MWh}$.

Taking into account the interruption parameters listed in Table 2, the following results are obtained (Table 3).

Table 2. Interruption parameters. C\&I, Commercial and Industrial.

\begin{tabular}{ccc}
\hline Customer Category & No. of Customers & Average Usage \\
\hline & & (Annual MWh) \\
\hline Medium and Large C\&I (Over 50,000 Annual kWh) & 0 & 459 \\
Small C\&I (Under 50,000 Annual kWh) & 50 & 38.9 \\
Residential & 200 & 6.4 \\
C\&I Industry Percentages & Medium and Large C\&I & Small C\&I \\
Construction & $2.00 \%$ & $9.50 \%$ \\
Manufacturing & $17.10 \%$ & $5.00 \%$ \\
All Other Industries & $80.90 \%$ & $85.50 \%$ \\
Total & $100.00 \%$ & $100.00 \%$ \\
\hline
\end{tabular}


Table 2. Cont.

\begin{tabular}{ccc}
\hline Customer Category & No. of Customers & Average Usage \\
\hline Percent of C\&I Customers with: & & (Annual MWh) \\
No or Unknown Backup Equipment & Medium and Large C\&I & Small C\&I \\
Backup Generation or Power Conditioning & $54.40 \%$ & $70.40 \%$ \\
Backup Generation and Power Conditioning & $37.20 \%$ & $26.20 \%$ \\
Total & $8.40 \%$ & $3.40 \%$ \\
Residential Customer Characteristics & $100.00 \%$ & $100.00 \%$ \\
Median Household Income & Estimate & \\
Distribution of Outages by Time of Day & $20,000 €$ & \\
Morning (6 a.m.-12 p.m.) & Estimated Percentage & \\
Afternoon (12 p.m.-5 p.m.) & $54.47 \%$ & \\
Evening (5 p.m.-10 p.m.) & $29.49 \%$ & \\
Night (10 p.m.-6 a.m.) & $5.23 \%$ & \\
Total & $10.81 \%$ & \\
Distribution of Outages by Time of Year & $100.00 \%$ & \\
Summer (June-September) & Estimated Percentage & \\
Non-Summer (October-May) & $34.72 \%$ & \\
Total & $65.28 \%$ & $100.00 \%$ \\
\hline
\end{tabular}

Table 3. Interruption cost estimates.

\begin{tabular}{|c|c|c|c|c|c|}
\hline Sector & $\begin{array}{l}\text { No. of } \\
\text { Customers }\end{array}$ & $\begin{array}{l}\text { Cost per Event } \\
\quad(2016 €)\end{array}$ & $\begin{array}{l}\text { Cost per Average } \\
\text { kW }(2016 €)\end{array}$ & $\begin{array}{l}\text { Cost per Unserved } \\
\text { kWh }(2016 €)\end{array}$ & $\begin{array}{c}\text { Total Cost of } \\
\text { Sustained } \\
\text { Interruptions }(2016 €)\end{array}$ \\
\hline Medium and Large C\&I & 0 & 52.60 & 2101.69 & 0.00 & 0.00 \\
\hline Residential & 200 & 3.36 & 4.60 & 184.94 & $20,265.39$ \\
\hline All Customers & 250 & 124.26 & 92.19 & 3689.62 & $931,892.59$ \\
\hline
\end{tabular}

Commercial activities on the island are not significant. Most of the companies are commercial companies with low turnover, which employ less than ten employees. As already mentioned, estimating the interruption costs is a very complex task that often requires visiting the site in order to understand the impacts that a power cut can create. In order to take into consideration the costs related to outage events and to investigate the resilience of the system, assumptions regarding the maximum Curtailment Rate (CR) and the variable costs were taken into account as in Table 4 .

Table 4. Curtailment parameters. CR, Curtailment Rate.

\begin{tabular}{ccc}
\hline Priority Level & Variable Cost $(\boldsymbol{€} / \mathbf{k W h})$ & Max Curtailment Load \\
\hline Low CR & 3 & $20 \%$ \\
Mid CR & 15 & $60 \%$ \\
High CR & 25 & $20 \%$ \\
\hline
\end{tabular}

Once all input parameters have been updated, the run optimization is launched in order to establish the reference costs and $\mathrm{CO}_{2}$ emissions. Subsequently, after adding $1 \%$ to these values, which is the default solver precision, the reference costs and $\mathrm{CO}_{2}$ emissions are determined to be the global settings, and various economic, environmental and other constraints related to investments preferences are set. At this stage, one can enable or disable investments to be discrete and continuous DG technologies, sales from conventional technologies and/or photovoltaics, to determine the interest rate and the maximum Payback Period (PBP) and, finally, to determine the preferred objective. 


\section{Results and Discussion}

The process is launched, and the reference costs and $\mathrm{CO}_{2}$ values, as well as data about outage events are shown in Tables 5 and 6.

Table 5. Reference case summary.

\begin{tabular}{|c|c|c|c|c|}
\hline & $\begin{array}{l}\text { Annual Electricity Costs } \\
(\mathbf{k} €)\end{array}$ & $\begin{array}{c}\text { Annual Outage Events Costs } \\
(\mathbf{k} €)\end{array}$ & $\begin{array}{c}\text { Total Annual Energy Costs * } \\
(\mathbf{k} €)\end{array}$ & $\begin{array}{c}\text { Total Annual } \mathrm{CO}_{2} \\
\text { Emissions (Metric Tons) }\end{array}$ \\
\hline Investment scenario & 472.16 & 440.57 & 912.73 & 1977 \\
\hline
\end{tabular}

Table 6. Unserved energy due to outage events and related costs by priority level.

\begin{tabular}{ccccc}
\hline & Low CR & Mid CR & High CR & Total \\
\hline Outages costs $(\mathrm{k} €)$ & 25.83 & 309.94 & 104.81 & 440.57 \\
Unserved energy $(\mathrm{kWh})$ & 8610 & 20,662 & 4192 & 33,465 \\
\hline
\end{tabular}

The annual average electricity generation cost is $147.11 € / \mathrm{MWh}$. It can been seen that the corresponding total annual cost is $472.16 \mathrm{k} €$, while the cost regarding the power interruptions has been estimated to be almost the same, $440.57 \mathrm{k} €(48 \%)$ of the total annual energy costs for the year 2015. As reported, for this year, the System Average Interruption Frequency Index (SAIFI) was 30 events per customer, with an average duration (CAIDI) of $1.5 \mathrm{~h}$ per event. High interruption costs derive from the fact that Tilos Island is subjected to many outage events, during which all priority loads are cut off.

Given that the average load demand of Tilos Island was $370 \mathrm{~kW}$, the CAIDI was $1.5 \mathrm{~h}$ per event, the high priority load is $20 \%$ of the total demand, the minimum state of charge is $10 \%$ of total capacity of batteries and the depth of discharge is set to $40 \%$ for normal operation so as to achieve a longer life cycle, the minimum required energy of the battery bank, in order to cover the high priority load in the case of an outage lasting 1.5 hours, is calculated from Equation (4).

$$
E=\frac{\text { Annual average load demand } \times \text { high priority load }(\text { as share of total }) \times C A I D I}{\text { full } S O C-(D O D \text { set point }+\min S O C)}
$$

where SOC is the State Of Charge and DOD the Depth Of Discharge. In this case, the minimum capacity of the battery bank has been set at $225 \mathrm{kWh}$. After the investment analysis, the following results (Table 7) overview was obtained.

Table 7. Cost minimization summary.

\begin{tabular}{ccccc}
\hline & $\begin{array}{c}\text { Annual Electricity Costs } \\
(\mathbf{k \ell})\end{array}$ & $\begin{array}{c}\text { Annual Outage Events Costs } \\
(\mathbf{k \ell})\end{array}$ & $\begin{array}{c}\text { Total Annual Energy Costs * } \\
(\mathbf{k \ell})\end{array}$ & $\begin{array}{c}\text { Total Annual CO } \\
\text { Emissions (Metric Tons) }\end{array}$ \\
\hline Reference & 472.16 & 440.57 & 921.86 & \\
Investment Scenario & 18.62 & 1.49 & -2.50 & 1997 \\
Total Savings (\%) & $96.1 \%$ & $99.7 \%$ & $100.3 \%$ & 69 \\
Operating Expenses & & & $122 \%$ & \\
(OPEX) Savings (\%) & & & & \\
\hline & * Including annualized capital costs, electricity sales and $\mathrm{CO}_{2}$ costs.
\end{tabular}

As expected, the operational expenses have been drastically decreased compared to the reference case. In addition, even if the annual capital depreciation is included, again, the cost is much lower. The cost optimal solution involves a high capacity of PV generators and wind turbines (Figure 3). The high capacity of wind turbines may bring several technical impacts to the local distribution network. Thereafter, constraints regarding land use were set (Table 8), and the cost minimization process was performed once again. 


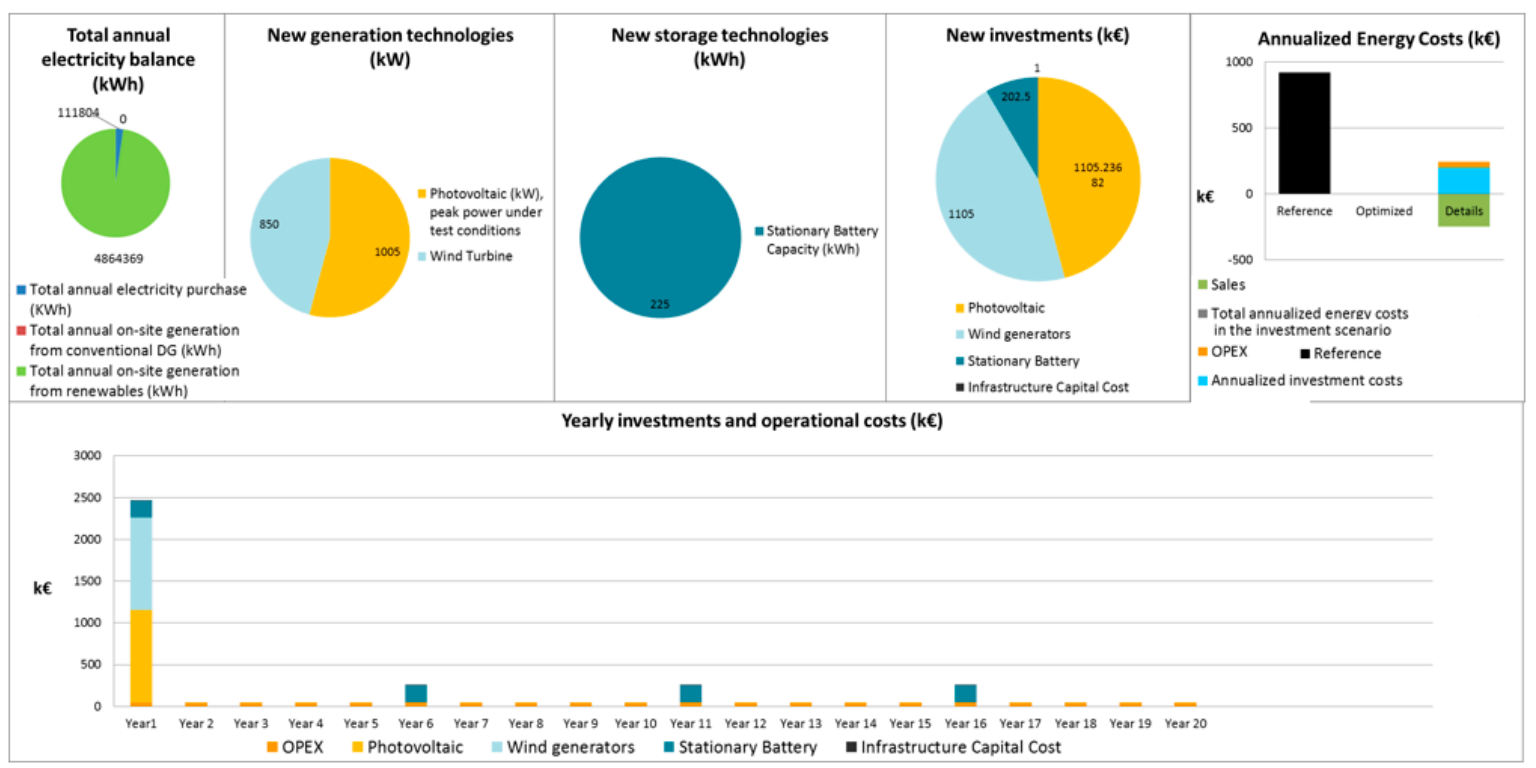

Figure 3. Summary results of the cost optimal solution.

Table 8. Cost minimization summary, including land use constraints.

\begin{tabular}{ccccc}
\hline & $\begin{array}{c}\text { Annual Electricity Costs } \\
(\mathbf{k \ell})\end{array}$ & $\begin{array}{c}\text { Annual Outage Events Costs } \\
(\mathbf{k \ell})\end{array}$ & $\begin{array}{c}\text { Total Annual Energy Costs * } \\
(\mathbf{k \ell})\end{array}$ & $\begin{array}{c}\text { Total Annual CO } \\
\text { Emissions (Metric Tons) }\end{array}$ \\
\hline Reference & 472.16 & 440.57 & 921.86 & 1977 \\
Investment scenario & 18.62 & 4.89 & 124.18 & 123 \\
Total Savings (\%) & $96.1 \%$ & $98.9 \%$ & $86.5 \%$ & $93.8 \%$ \\
OPEX Savings (\%) & & \multicolumn{1}{c}{$102.6 \%$} & \\
\hline \multicolumn{5}{c}{ * Including annualized capital costs, electricity sales and $\mathrm{CO}_{2}$ costs. }
\end{tabular}

Although a slight decrease is observed, both total and OPEX savings are still very high compared to the reference case. The following table presents the load curtailments and the corresponding costs by priority level (Table 9).

Table 9. Load curtailments during outage events and related costs by priority level—cost minimization.

\begin{tabular}{lcccc}
\hline & Low CR & Mid CR & High CR & Total \\
\hline Load curtailment costs $(\mathrm{k} €)$ & 2.07 & 2.82 & 0.00 & 4.89 \\
Unserved energy $(\mathrm{kWh})$ & 690 & 188 & 0 & 878 \\
\hline
\end{tabular}

The following key indicators give a more detailed picture of the cost optimal solution. It can be seen (Table 10) that RES generation exceeds the total electricity demand.

Table 10. Key indicators of the cost optimal solution.

\begin{tabular}{cc}
\hline Key Indicators & \\
\hline Total electricity sales $(\mathrm{k} €)$ & 84.25 \\
Total annual electricity purchase $(\mathrm{kWh})$ & 33,129 \\
Total annual on-site generation from renewables $(\mathrm{kWh})$ & $3,652,441$ \\
RES share of total electric load & $113 \%$ \\
Estimated total annual fuel consumption * $(\mathrm{kWh})$ & 585,742 \\
\hline * Including fuel used by the utility, assuming average macro efficiency.
\end{tabular}

Figure 4 illustrates the investment decisions, the new generation technologies to be installed, as well as the annualized energy costs in comparison with the reference case. It is obvious that the capacity 
of RES has been restricted. The new proposed investment now includes $450 \mathrm{~kW}$ of photovoltaics and $750 \mathrm{~kW}$ of wind turbines. The new model includes $225 \mathrm{kWh}$ of stationary batteries, as this is the minimum capacity that has been defined. Although new capital costs for new renewable energy technologies are suggested, annual operational expenditures are lower, and the savings obtained are enough to repay investments within the boundaries set by financial constraints. Besides the operational expenses, a dramatic reduction is observed in $\mathrm{CO}_{2}$ emissions. This is because the constraints that were previously set for available technologies for DER investment allow only renewable energy-based technologies to be used. Therefore, the balance of $6.2 \%$ of $\mathrm{CO}_{2}$ emissions is due to the small amount of electricity purchases that still exist in this model.

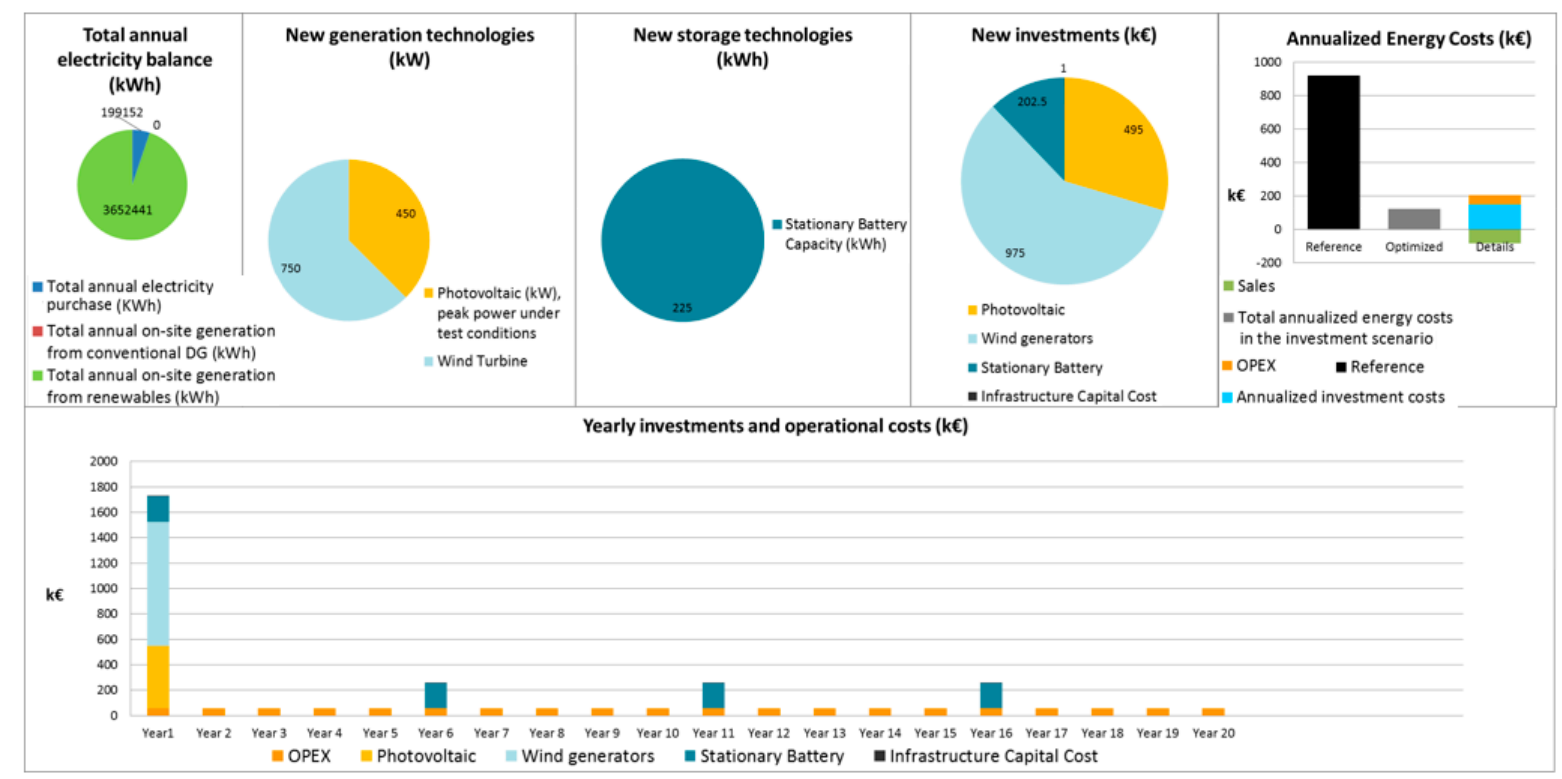

Figure 4. Summary results of the cost optimal solution including land use constraints.

Figure 5A illustrates the optimal electricity dispatch of the optimal solution. As is shown, the bulk of the original electric load is met by DER technologies. While the electric load demand is higher than the electricity produced by DER generators, the balance is provided by stationary batteries, otherwise by the main grid. The electricity dispatch of a week-day of August is depicted in Figure 5B. The electricity demand is covered even in August when there is the highest electric demand. Some hours of the day, the microgrid imports energy from the utility in order to meet the power demand, while some others export energy from photovoltaics to the grid. The export of energy from photovoltaics coincides with the peak and mid-peak energy demand and ToU rates. The stationary batteries provide energy when necessary either to meet the energy demand or to help with the optimal dispatching. Figure 5C represents what happened when an outage event occurred and the generation storage power was not sufficient to meet the loads. Load curtailments by priority level are applied when necessary. In this day, the outage event lasted three hours during which, low and medium priority load shedding had to take effect. 


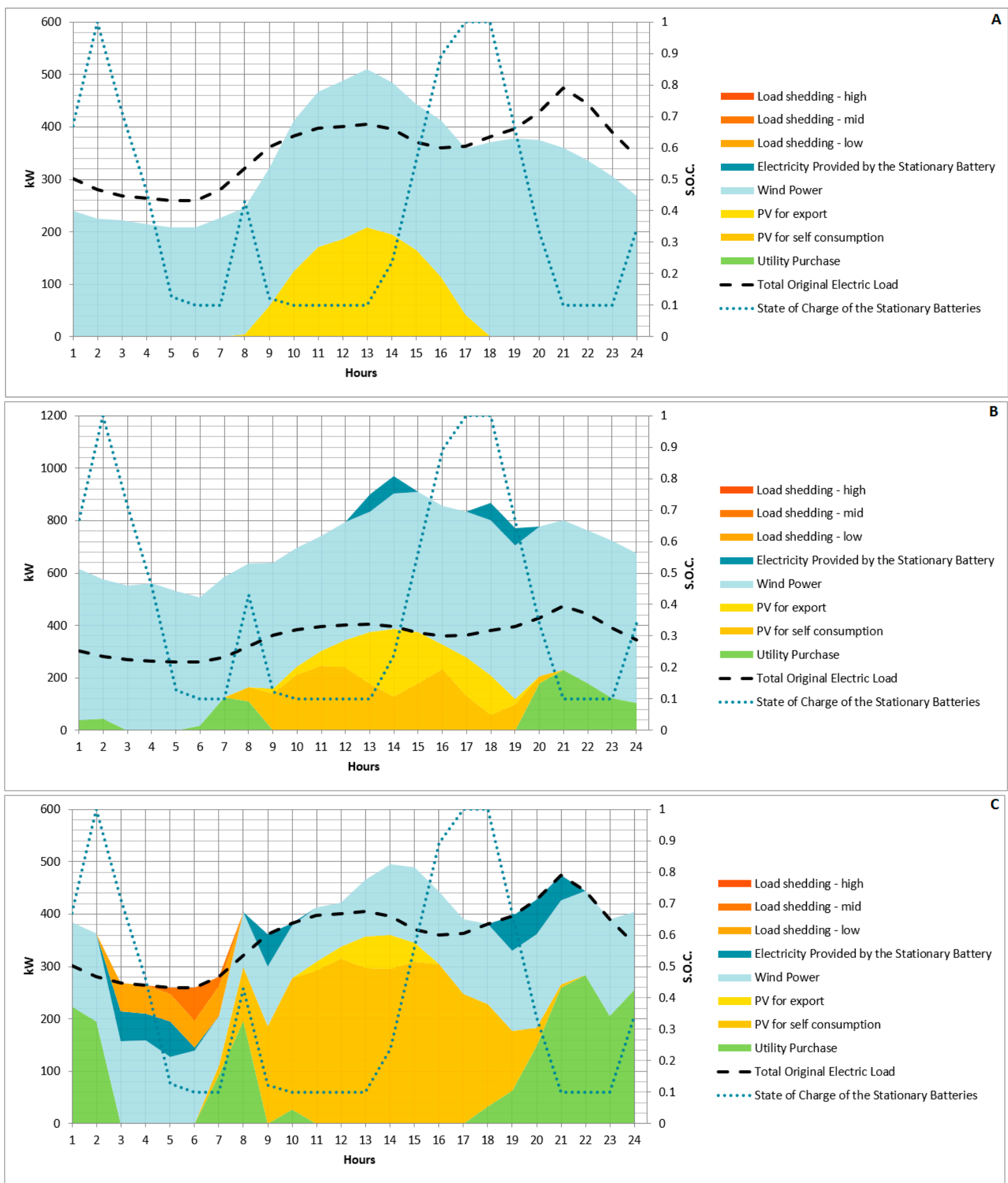

Figure 5. Optimal dispatch for electricity technologies (A); optimal dispatch for electricity technologies (August week-day) (B); optimal dispatch for electricity technologies (May emergency week-day) (C).

The reduction of $\mathrm{CO}_{2}$ emissions has an economic dimension as the cost of allowance production of $\mathrm{CO}_{2}$ emissions in the reference case scenario was calculated to be about $8000 €$, where this value is about $1.67 \%$ of the total marginal electricity production cost (interruption costs excluded). However, the $\mathrm{CO}_{2}$ emissions have mainly social impacts particularly when talking about communities living next to large thermal plants. Via the DER-CAM analysis, interesting results have shown that the investment is not feasible, as the annualized investment cost is too high, and the total annual expenditures are higher than the reference case scenario (Table 11). The $\mathrm{CO}_{2}$ savings were $97.1 \%$ instead of $100 \%$, as expected. Although this solution includes huge storage capacity, the load curtailment costs are 
much greater than those of the previous cost optimization scenario. This is because the environmentally optimal solution does not give any weight to the economic dimension of the load curtailments.

Table 11. $\mathrm{CO}_{2}$ minimization summary.

\begin{tabular}{ccccc}
\hline & $\begin{array}{c}\text { Annual Electricity Costs } \\
(\mathbf{k \ell})\end{array}$ & $\begin{array}{c}\text { Annual Outage Events Costs } \\
(\mathbf{k \ell})\end{array}$ & $\begin{array}{c}\text { Total Annual Energy Costs * } \\
(\mathbf{k \ell})\end{array}$ & $\begin{array}{c}\text { Total Annual CO } \\
\text { Emissions (Metric Tons) }\end{array}$ \\
\hline Reference & 472.16 & 440.57 & 921.86 & 1997 \\
Investment scenario & 16.09 & 789.46 & 1293.67 & 59 \\
Total Savings (\%) & $96.6 \%$ & $-79.2 \%$ & $-40.3 \%$ & $97.1 \%$ \\
OPEX Savings (\%) & & \multicolumn{3}{c}{$8.7 \%$} \\
\hline
\end{tabular}

A multi-objective analysis was implemented after having carried out the cost and the $\mathrm{CO}_{2}$ optimization processes. This process gave a number of solutions by changing the weighting factors of cost and $\mathrm{CO}_{2}$ objectives, taking into consideration different aspects of the problem and finding the trade-off between incompatible objectives. A compromise solution, mutually beneficial for all stakeholders, was reached. The maximum annual costs and the maximum annual $\mathrm{CO}_{2}$ emissions allowed in the multi-objective simulation were defined. These values were considered as the scaling factors of the multi-objective optimization and obtained by finding the cost of $\mathrm{CO}_{2}$ minimization run and the $\mathrm{CO}_{2}$ emissions of the cost minimization run. In this stage, several optimization runs should be performed. Table 12 lists the combinations of weight factors that have been carried out, e.g. weight factor of $\mathrm{CO}_{2}\left(\mathrm{WCO}_{2}\right)$.

Table 12. Weighting factor combinations carried out.

\begin{tabular}{llllllllllll}
\hline Wcost & $\mathbf{1}$ & $\mathbf{0 . 9}$ & $\mathbf{0 . 8}$ & $\mathbf{0 . 7}$ & $\mathbf{0 . 6}$ & $\mathbf{0 . 5}$ & $\mathbf{0 . 4}$ & $\mathbf{0 . 3}$ & $\mathbf{0 . 2}$ & $\mathbf{0 . 1}$ & $\mathbf{0}$ \\
\hline $\mathrm{WCO}_{2}$ & 0 & 0.1 & 0.2 & 0.3 & 0.4 & 0.5 & 0.6 & 0.7 & 0.8 & 0.9 & 1 \\
\hline
\end{tabular}

The weight objective function used by DER-CAM is (Equation (5)):

$$
\begin{gathered}
\min f=\text { MultiObjectiveWcost } \times\left(\frac{\text { Total annual cost }}{\text { MultiObjectiveMaxCost }}\right) \\
+ \text { MultiObjectiveWCO } \mathrm{C}_{2} \times\left(\frac{\text { Total annual } \mathrm{CO}_{2}}{\text { MultiObjectiveMaxCO}}\right)
\end{gathered}
$$

In order to present the output of the multi-objective optimization, the case with 0.7 cost and $0.3 \mathrm{CO}_{2}$ weight factors has been selected. The following table shows that the total annual savings are $80.6 \%$, and the OPEX savings are $103.3 \%$. Compared with the cost optimal solution, the annual electricity generation costs are slightly higher, while the savings of interruption costs reach $100 \%$ (Tables 13 and 14).

\begin{tabular}{|c|c|c|c|c|}
\hline & $\begin{array}{l}\text { Annual Electricity Costs } \\
(\mathbf{k} €)\end{array}$ & $\begin{array}{c}\text { Annual Outage Events Costs } \\
(\mathbf{k} €)\end{array}$ & $\begin{array}{c}\text { Total Annual Energy Costs * } \\
(\mathbf{k} €)\end{array}$ & $\begin{array}{c}\text { Total Annual } \mathrm{CO}_{2} \\
\text { Emissions (Metric Tons) }\end{array}$ \\
\hline Reference & 472.16 & 440.57 & 921.86 & 1997 \\
\hline Investment scenario & 28.70 & 0.74 & 178.79 & 114 \\
\hline OPEX Savings (\%) & & & $103.3 \%$ & \\
\hline
\end{tabular}

Table 13. Multi-objective (70/30) optimization scenario summary.

Table 14. Curtailment costs, multi-objective (70/30) optimization.

\begin{tabular}{ccccc}
\hline & Low CR & Mid CR & High CR & Total \\
\hline Load curtailment costs $(\mathrm{k} €)$ & 0.74 & 0.00 & 0.00 & 0.74 \\
Unserved energy $(\mathrm{kWh})$ & 7812 & 0 & 0 & 7812 \\
\hline
\end{tabular}


Figure 6 summarizes all the results of the multi-objective (70/30) optimal solution. The main difference from the previous single-objective optimal solutions is that the electricity storage capacity from stationary batteries is higher $(518 \mathrm{kWh})$. This increases the reliability of the system, reducing the power cuts and the corresponding costs. It is worth noting that the price of batteries is expected to highly decrease in the next few years, and this cost should be adjusted. The issue of how resilient the microgrid is to outage events is answered in Figure 7. When an outage event occurs and the energy demand is greater than the local generation capacity and available storage, the load curtailment technique is applied with low priority, in order to cope with this situation. Otherwise, if no local generation and energy storage are available, such as the reference case, this would be an outage event along with all the negative impacts described above. Comparing with Figure 5C, for the same day, with the same loads and for the same 3-h outage event, this solution seems more reliable, giving better electricity dispatch due to the higher capacity of the stationary batteries, for the same capacity of PV and wind turbine generators. In this case, load shedding is applied only in low priority loads.

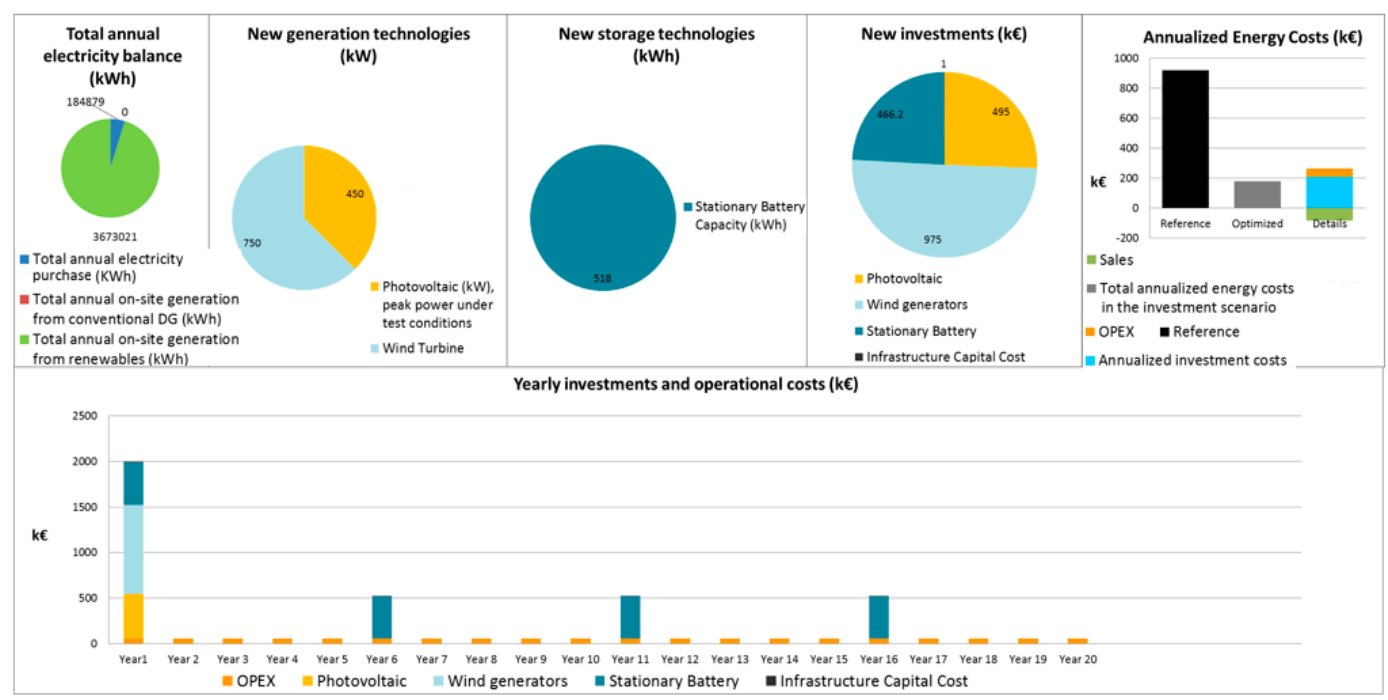

Figure 6. Summary of the results of the multi-objective (70/30) optimal solution.

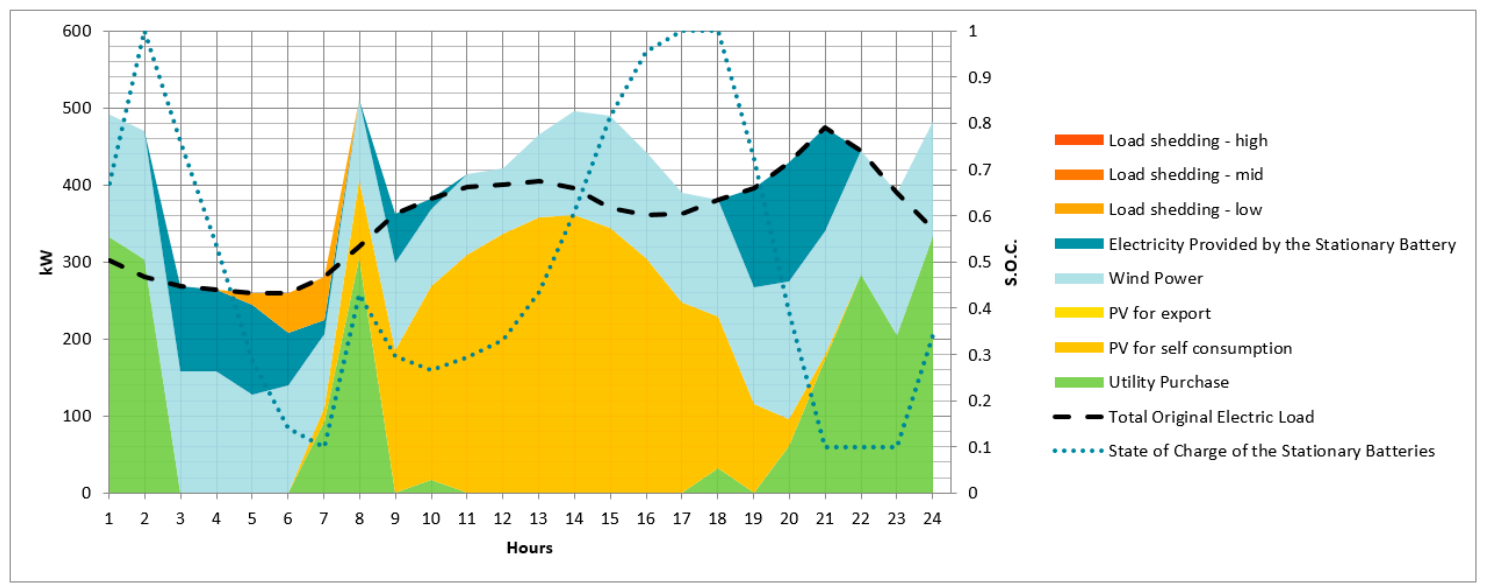

Figure 7. Optimal dispatch for electricity technologies: multi-objective (70/30) optimal solution (May emergency week-day).

It is remarkable that in this optimal solution, the load curtailment event that is illustrated in Figure 7 takes place only one day of a year. 
After performing the same task ten more times for all combinations referred to in Table 12, the following output table was obtained (Table 15).

Table 15. Output summary of multi-objective optimization analysis for different combinations of weighting factors.

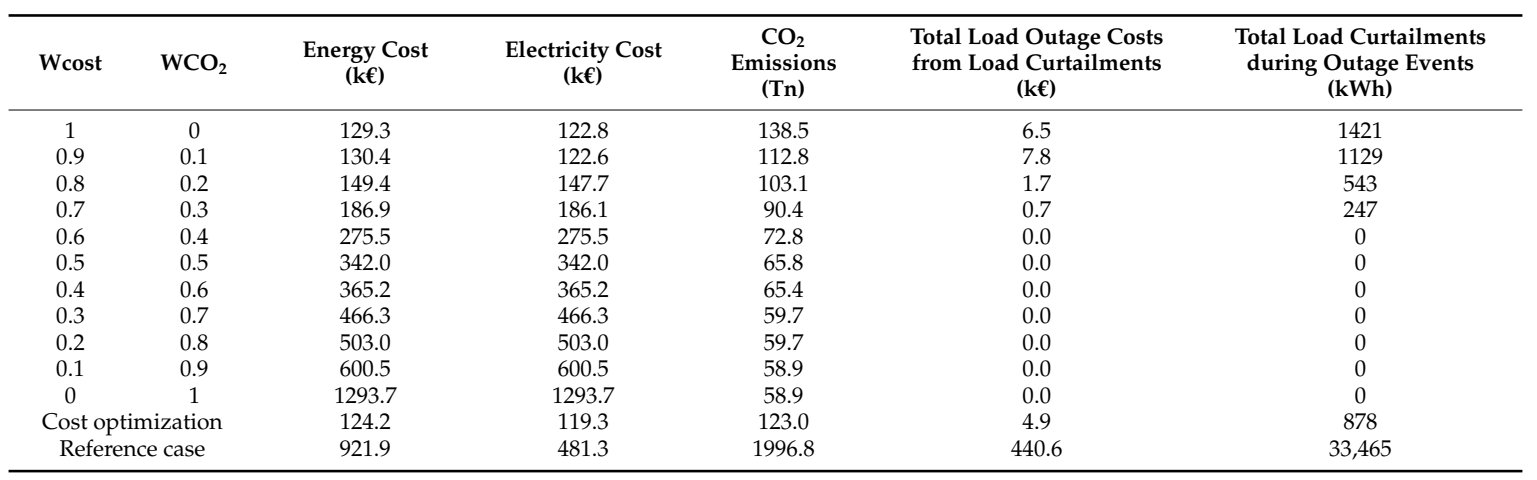

As expected, as the $\mathrm{CO}_{2}$ weighting factor tends to 1 and correspondingly the cost weighting factor tends to zero, the energy costs increase and the $\mathrm{CO}_{2}$ emissions decrease, respectively. The same happens to the load curtailments from the Wcost $0.6 / \mathrm{WCO}_{2} 0.4$ till they become zero. These findings are graphically represented in Figure 8. In the two vertical axis is what the local community and government consider as key element, while in the horizontal axis is what the DER developer considers as the main objective, whether it is an investor or the DSO.

In the left vertical axis, the $\mathrm{CO}_{2}$ emissions that represent a main object for both the policy makers aiming to get the $2020 \mathrm{EU}$ energy targets and for societies as an environmental pollution index are placed. The right vertical axis presents the load curtailments during an outage event given in $\mathrm{kWh}$ that represent the reliability, security and power quality of the microgrid. The greater is the unserved energy, the greater is the insecurity and unreliability of the microgrid and the lower is the level of end user satisfaction. The horizontal axis illustrates the total electricity costs including the annualized capital costs, the electricity sales and purchases and $\mathrm{CO}_{2}$ emission costs. In other words, the total electricity cost represents the total annualized electricity generation and operation costs for the DER developer in order to meet the electricity demand of the local microgrid.

A win-win solution for all stakeholders could be the fifth in the series, for which the weight factors are 0.6 for cost and 0.4 for $\mathrm{CO}_{2}$, respectively, as it presents high reliability without load curtailments, quite reduced emissions of $96.3 \% \mathrm{CO}_{2}$ savings against the reference case and satisfactory profits for the investor, making the investment feasible and quite attractive.

Although in this solution, $\mathrm{CO}_{2}$ emission savings (96.3\%) are not the maximum they could be, there is no appreciable difference between the maximum possible savings, which is $97.1 \%$, and the preferred solution, while comparing the two aforementioned solutions, the total annualized costs are more than doubled in the second one. 


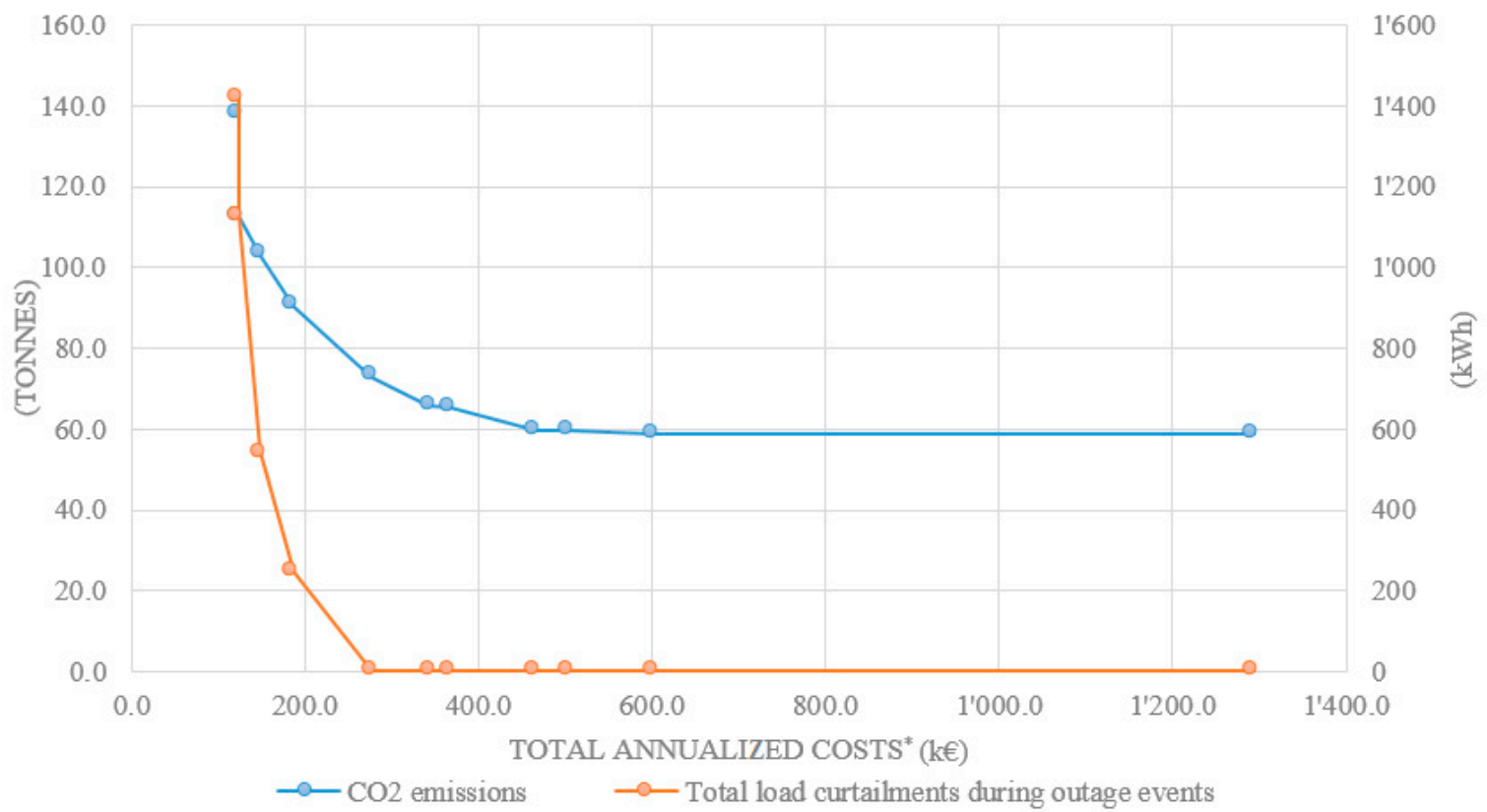

*including annualized capital costs, electricity sales and purchases and $\mathrm{CO}_{2}$ costs

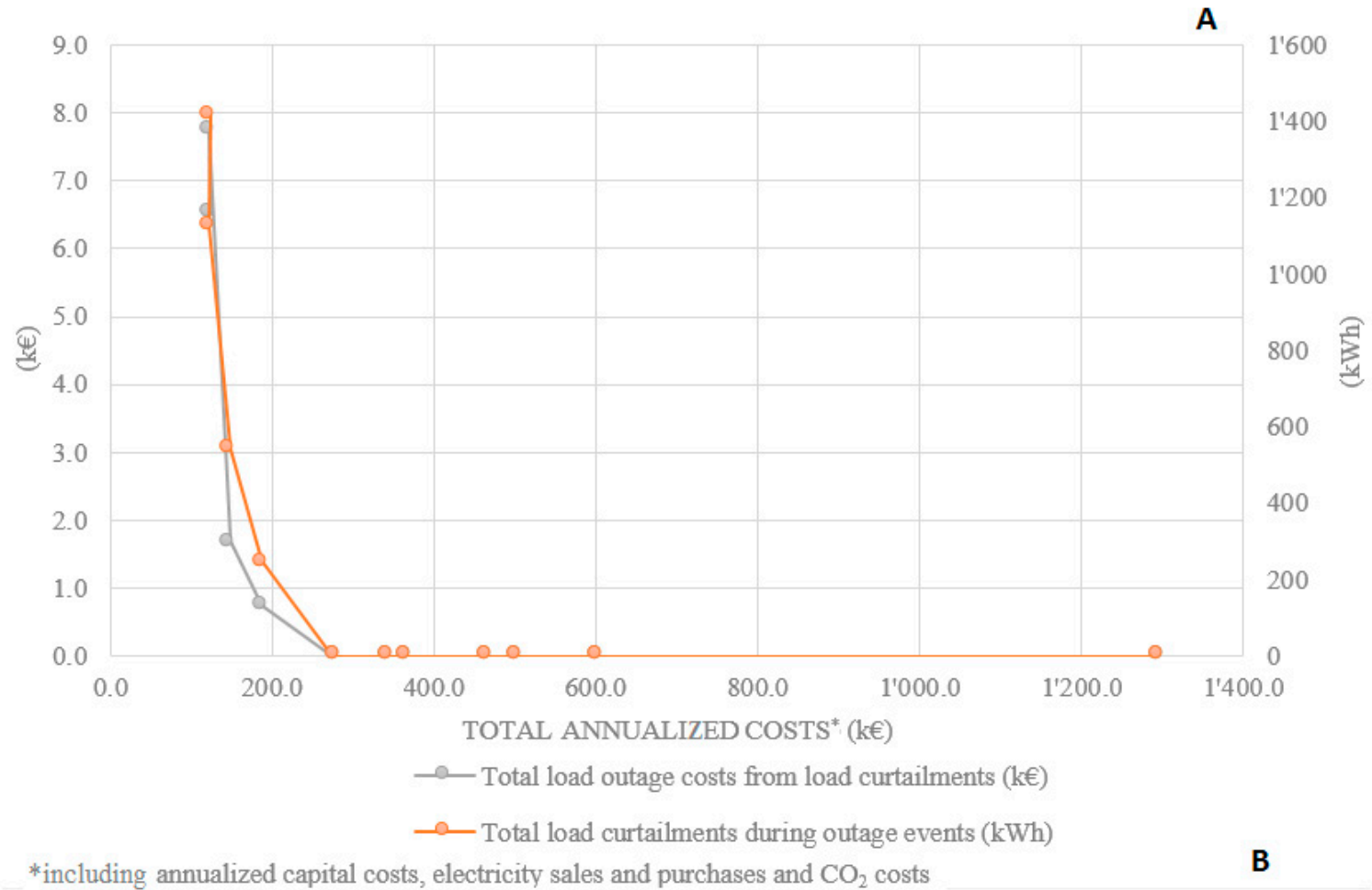

Figure 8. Non-dominated optimal solution set, of DER planning and operation, from different perspectives (A); non-dominated optimal solution set, of DER planning and operation, taking into consideration reliability and economic objectives (B).

\section{Conclusions}

The possibility of replacing the existing autonomous power plants with RES-based ones along with appropriate energy storage technologies was investigated thoroughly in this study. A case study of a small Greek island, which is confronted often with energy shortages, was studied for evaluating the feasibility of DER deployment at this scale. DER-CAM uses a Mixed Integer Linear Program (MILP) solver that finds optimal invests. The methods used were both the weighted-sum method 
when running the multi-objective optimization and the $\varepsilon$-constrained method when running single objectives like cost or $\mathrm{CO}_{2}$ optimization. By changing either the weighting factors of the objectives or the master objective, several optimal solutions were obtained. In this approach, the decision making follows the multi-objective optimization process, by evaluating the possible solutions and concluding on the most preferable one.

In the case study, so as to restrict the visual impact of the wind turbines and to increase the capacity steps, small wind turbines of $50 \mathrm{~kW}$ have been selected. Given that the accuracy of the MILP solver that DER-CAM uses is $1 \%$ and after the aforementioned assumptions and constraints have been defined, the optimal non-dominated set of proposed solutions presented in the previous section are considered as real solutions to the real problem. The fact that seven of a total of eleven proposed solutions were found economically feasible suggests that DER investments based on renewable energy technologies can be deployed at a large scale and be beneficial for all stakeholders. Furthermore, DER development implies many external benefits for the local communities, while making them more energy independent. The improved power quality and reliability of the system can have economic benefits in terms of commercial activities.

Acknowledgments: Special thanks to the researchers of the Lab of Soft Energy Applications \& Environmental Protection, Technological Educational Institute (TEI) of Piraeus, which provided data on load demand and power outages for Tilos Island to the first author of the paper under the frames of the Heriot Watt MSc in Energy program in order to conduct his MSc thesis research. We would also like to thank the researchers of the Lawrence Berkeley National Laboratory and more specific Mr. Michael Stadler (Lawrence Berkeley National Laboratory, 1 Cyclotron Road, MS: 90-1121, Berkeley, California 94720, USA) for giving us access to the full DER-CAM Web-Optimization Service.

Author Contributions: P.M. and G.X. conceived of and designed the software simulations. P.M. performed the simulations. P.M., G.X. and L.M.-P. analyzed the data. L.M.-P. contributed to the analysis. P.M. and G.X. wrote the paper.

Conflicts of Interest: The authors declare n conflict of interest.

\section{References}

1. Marnay, C.; Kawaan, C.P.; Blanco, R.; Osborn, J.G.; Hamachi, K.S.; Rubio, F.J. Integrated Assessment of Dispersed Energy Resources Deployment-LBNL No. 46082. 2000. Available online: https:/ / escholarship. org/uc/item/22f8m8t1 (accessed on 17 March 2016).

2. MSc in Energy, Heriot-Watt University. 2017. Available online: https://www.hw.ac.uk/study/uk/ postgraduate/energy.htm (accessed on 26 April 2017).

3. Momber, I.; Gómez, T.; Venkataramanan, G.; Stadler, M.; Beer, S.; Lai, J.; Marnay, C.; Battaglia, V. Plug-in electric vehicle interactions with a small office building: An economic analysis using DER-CAM. In Proceedings of the IEEE PES General Meeting, Providence, RI, USA, 25-29 July 2010.

4. Cardoso, G.; Stadler, M.; Bozchalui, M.C.; Sharma, R.; Marnay, C.; Barbosa-Povoa, A.; Ferrao, P. Stochastic programming of vehicle to building interactions with uncertainty in PEVs driving for a medium office building. In Proceedings of the IEEE 39th Annual Conference on Industrial Electronics Society, Vienna, Austria, 10-13 November 2013; pp. 7648-7653.

5. Mendes, G.; Ioakimidis, C.; Ferrão, P. On the planning and analysis of Integrated Community Energy Systems: A review and survey of available tools. Renew. Sustain. Energy Rev. 2011, 15, 4836-4854. [CrossRef]

6. Beer, S.; Gómez, T.; Dallinger, D.; Momber, I.; Marnay, C.; Stadler, M.; Lai, J. An economic analysis of used electric vehicle batteries integrated into commercial building microgrids. IEEE Trans. Smart Grid 2012, 3, 517-525. [CrossRef]

7. DeForest, N.; Mendes, G.; Stadler, M.; Feng, W.; Lai, J.; Marnay, C. Optimal deployment of thermal energy storage under diverse economic and climate conditions. Appl. Energy 2014, 119, 488-496. [CrossRef]

8. Milan, C.; Stadler, M.; Cardoso, G.; Mashayekh, S. Modeling of non-linear CHP efficiency curves in distributed energy systems. Appl. Energy 2015, 148, 334-347. [CrossRef]

9. Braslavsky, J.H.; Wall, J.R.; Reedman, L.J. Optimal distributed energy resources and the cost of reduced greenhouse gas emissions in a large retail shopping centre. Appl. Energy 2015, 155, 120-130. [CrossRef] 
10. Alarcon-Rodriguez, A.; Ault, G.; Galloway, S. Multi-objective planning of distributed energy resources: A review of the state-of-the-art. Renew. Sustain. Energy Rev. 2010, 14, 1353-1366. [CrossRef]

11. Ren, H.; Zhou, W.; Nakagami, K.; Gao, W.; Wu, Q. Multi-objective optimization for the operation of distributed energy systems considering economic and environmental aspects. Appl. Energy 2010, 87, 3642-3651. [CrossRef]

12. Colak, I.; Sagiroglu, S.; Fulli, G.; Yesilbudak, M.; Covrig, C.F. A survey on the critical issues in smart grid technologies. Renew. Sustain. Energy Rev. 2016, 54, 396-405. [CrossRef]

13. Colmenar-Santos, A.; Reino-Rio, C.; Borge-Diez, D.; Collado-Fernández, E. Distributed generation: A review of factors that can contribute most to achieve a scenario of DG units embedded in the new distribution networks. Renew. Sustain. Energy Rev. 2016, 59, 1130-1148. [CrossRef]

14. Cataliotti, A.; Cosentino, V.; Di Cara, D.; Russotto, P.; Telaretti, E.; Tinè, G. An Innovative Measurement Approach for Load Flow Analysis in MV Smart Grids. IEEE Trans. Smart Grid 2016, 7, 889-896. [CrossRef]

15. Artale, G.; Cataliotti, A.; Cosentino, V.; Guaiana, S.; Di Cara, D.; Tinè, G. Development of a coupling system for medium voltage power line communication in the CENELEC A frequency band. In Proceedings of the IEEE International Workshop on Applied Measurements for Power Systems (AMPS), Aachen, Germany, 28-30 September 2016; pp. 1-6.

16. Cataliotti, A.; Cosentino, V.; Di Cara, D.; Guaiana, S.; Panzavecchia, N.; Tinè, G. A New Solution for Low-Voltage Distributed Generation Interface Protection System. IEEE Trans. Instrum. Meas. 2015, 64, 2086-2095. [CrossRef]

17. Kabalci, E.; Kabalci, Y. A measurement and power line communication system design for renewable smart grids. Meas. Sci. Rev. 2013, 13, 248-252. [CrossRef]

18. Ancillotti, E.; Bruno, R.; Conti, M. The role of communication systems in smart grids: Architectures, technical solutions and research challenges. Comput. Commun. 2013, 36, 16-97. [CrossRef]

19. Dalianis, G.; Nanaki, E.; Xydis, G.; Zervas, E. New Aspects to Greenhouse Gas Mitigation Policies for Low Carbon Cities. Energies 2016, 9, 128. [CrossRef]

20. Koroneos, C.; Xydis, G.; Polyzakis, A. The optimal use of renewable energy sources-The case of the new international "Makedonia” airport of Thessaloniki, Greece. Renew. Sustain. Energy Rev. 2010, 14, 1622-1628. [CrossRef]

21. Regulatory Authority of Energy. RAE Decision No. 468/2013. 2013. Available online: http:/ /www.rae.gr/site/ el_GR/categories_new/about_rae/actions/decision/2013/2013_A0468.csp (accessed on 1 November 2017). (In Greek)

22. Xydis, G. Wind energy to thermal and cold storage-A systems approach. Energy Build. 2013, 56, 41-47. [CrossRef]

23. U.S. Department of Energy. Interruption Cost Estimate (ICE) Calculator-BETA. 2016. Available online: http:/ / www.icecalculator.com/ (accessed on 5 March 2016).

24. Camacho, O.M.F.; Nørgård, P.B.; Rao, N.; Mihet-Popa, L. Electrical Vehicle Batteries Testing in a Distribution Network using Sustainable Energy. IEEE Trans. Smart Grid 2014, 5, 1033-1042. [CrossRef]

25. Mihet-Popa, L.; Koch-Ciobotaru, C.; Isleifsson, F.; Bindner, H. Development of tools for DER Components in a distribution network. In Proceedings of the 20th International Conference on Electrical Machines, Marseille, France, 2-5 September 2012; pp. 1022-1031.

26. Ackermann, T.; Cherevatskiy, S.; Brown, T.; Eriksson, R.; Samadi, A.; Ghandhari, M.; Söder, L.; Lindenberger, D.; Jägemann, C.; Hagspiel, S.; et al. Smart Modeling of optimal Integration of high Penetration of PV-Smooth PV. Final Report, Smooth PV Project. 2013. Available online: http:/ / www.smooth-pv.info (accessed on 1 November 2017).

27. Eurostat. Energy Production and Imports. 2014. Available online: http://epp.eurostat.ec.europa.eu/ statistics_explained/index.php/Energy_production_and_imports (accessed on 16 November 2014).

(C) 2017 by the authors. Licensee MDPI, Basel, Switzerland. This article is an open access article distributed under the terms and conditions of the Creative Commons Attribution (CC BY) license (http:/ / creativecommons.org/licenses/by/4.0/). 